\title{
GWAM-An Institutional Model to Address Watershed Impacts from Urbanization: Conceptual Framework
}

\author{
Thambirajah Saravanapavan'1, Eiji Yamaji² \\ ${ }^{1}$ Center for Water Resources, Tetra Tech, Inc., Fairfax, VA, USA \\ ${ }^{2}$ Department of International Studies, Graduate School of Frontier Sciences, The University of Tokyo, Tokyo, Japan \\ Email: tham.saravanapavan@tetratech.com,yamaji@edu.k.u-tokyo.ac.jp
}

How to cite this paper: Saravanapavan, T. and Yamaji, E. (2018) GWAM-An Institutional Model to Address Watershed Impacts from Urbanization: Conceptual Framework. Journal of Water Resource and Protection, 10, 896-905.

https://doi.org/10.4236/jwarp.2018.109052

Received: March 27, 2018

Accepted: September 15, 2018

Published: September 18, 2018

Copyright $\odot 2018$ by authors and Scientific Research Publishing Inc. This work is licensed under the Creative Commons Attribution International License (CC BY 4.0).

http://creativecommons.org/licenses/by/4.0/

\begin{abstract}
The urbanization process exerts negative multidisciplinary impacts on the integrity of natural watershed conditions. These impacts are best analyzed and addressed with local inputs, as many of these are site specific and require consistent local monitoring along with appropriate policies and regulations from conventional governance in an interdisciplinary platform. With the realization of the limitations to top-down and bottom-up watershed management approaches in addressing issues associated with urbanization, a conceptual framework for a hybrid approach that tries to effectively integrate the advantages of the two approaches while overcoming their respective limitations, the Grass root Watershed Management model (GWAM), is presented in this paper. The model is to establish a self-sustaining and effective institutional forum that can be used in watersheds across geographical and political boundaries while accommodating the urbanization process. GWAM consists of three crucial components: a common platform, a partnership among major groups of stakeholders, and a facilitation mechanism to conduct the watershed management at local lever or grass-root level. With effective integration of the governmental agencies and institutes at the top with the local residents and non-governmental organizations at the bottom, the concept is that the hybrid approach can serve as a self-sustaining model in achieving effective management of urbanization impacts.
\end{abstract}

\section{Keywords}

Watershed Management, Urbanization, Interdisciplinary, Top-Down, Bottom-Up, Institutional Model 


\section{Introduction}

Urban areas all over the world are growing at unprecedented rates, creating extensive urban landscapes. Natural lands, such as forest, wetlands, shrubs and bushes, have been converted to buildings, roads, parking lots, and urban turf lands. All these changes have altered the natural hydrology and associated physical, ecological, geomorphologic, and biological aspects of the watershed systems and subsequently the river ecosystem. Urbanization and its threat to the rivers are well documented and analyzed [1]-[6]. In general, urbanization resulted in flooding, water quality impairments, stream morphological instability, deficit in groundwater, and habitat and aquatic life impairments. Thus no single change defines urbanization; instead, the cumulative effects of various human activities in urban watersheds profoundly influence urban streams and their natural ecosystem. Because of this complexity, addressing the impacts of urbanization must combine knowledge of the biophysical processes and conditions that sustain a specific stream system with the local knowledge of the drivers of degradation in that system. More importantly, combining the social and human dimension to the knowledge of impacts, its sources, and causes is vital because humans are considered as the agent of urbanization. It requires a collaborated, committed, and continued (3C) approach of all sections of stakeholders in the watershed through an interdisciplinary forum within an effective watershed management context.

Traditionally, the management of watershed follows a top-down approach, in which uniform sets of structures, roles, and programs that are formulated at high levels to meet national goals and extend downward to provincial/state and local levels in a top-down manner [7]. Such approaches, while proven effective in implementing certain regulations and practices, were also subject to common criticisms such as lack of local input and insufficiency in addressing multidisciplinary challenges accustomed to local conditions [8]. The bottom-up approach emerges as part of the efforts to overcome the known limitations of the top-down approach, specifically fulfilling the limitation of local input in planning and decision making processes of watershed management in addressing multidisciplinary challenges [8] [9]. As effective as the bottom-up approach is in addressing the "overarching" issues of the top-down approach, the bottom-up approach is also criticized for issues such as tokenism, community uniformness, capacity limitation, lack of facilitator knowledge, and inequity [8] [9] [10] [11]. The third paradigm, which is a combination of both the top-down approach and the bottom-up approach, emerges only recently in watershed management [7] [11] [12]. With the realization that neither approach is able to effectively address watershed management issues single-handedly, the hybrid approach tries to effectively integrate the advantages of the two approaches while overcoming their respective limitations.

A conceptual framework for a hybrid approach that combines both the top-down and the bottom-up approach to specifically address urbanization 
challenges, grass root watershed management model (GWAM), is presented in this paper. The model is to establish a self-sustaining and effective institutional forum that can be used in watersheds across geographical and political boundaries while accommodating the urbanization process.

\section{Interdisciplinary Watershed Management}

\subsection{Interdisciplinary Approach}

Water resources problems are extremely complex and dynamic in time, and thus requiring solutions to cross traditional disciplinary and social boundaries. While anthropologists, geographers, political scientists, psychologists, and sociologists were not always involved in water resources research in the past, their contributions have to be recognized and effectively incorporated in the twenty-first century watershed management programs [13]. In addition, government entities, community groups, business and industrial organizations, and the public have to be included in the participatory and interdisciplinary approach [14]. The interdisciplinary approaches has been extended by the Global Water Partnership (2000) as well as the 2003 Summit on Sustainable development in Johannesburg, South Africa and Second (2000), Third (2003) and Fourth (2006) World Water Forums.

The development and maintenance of the interdisciplinary approach requires many elements. One element is the establishment of a strong knowledge base that derives from a comprehensive and interdisciplinary data network, systems, and models. The knowledge base will help design and implement informed water management policies and strategies [14]. A second element is the integrated action across all water management issues, which means that no singular solutions are sought and impacts and improvements across the spectrum of water management are evaluated [14]. A third element is the promotion of strong community awareness and participatory process, which is to enhance stakeholder involvement in the management and decision-making [14].

\subsection{Self-Sustaining Institutional Model}

It is natural that watershed management programs change and evolve over time. For example, programs often focus on one initial problem before expanding their interests to other issues [15]. Or they may increase the scope of their activities or geographic concern [16]. Watershed management programs, depending on their level of associations with the government, could have varying levels of endurance and stability [17]. All of these make it imperative and meaningful to develop self-sustaining institutional models for watershed management.

The development of self-sustaining institutional models faces several challenges. Such challenges include, but not limit to, the lack of effective forums for inviting and retaining stakeholders; the narrow focus, lack of implementation capability, poor public involvement, and limited coordination attributes; poor coordination and/or collaboration among state, local, and federal water-related 
agencies; and poor communications links among planners, managers, stakeholders, and others, etc.

Multiple solutions are also reported for building a successful institutional model for watershed management. This includes the creation of a stable framework that overcomes fragmentation and overlap of responsibilities; the use of institutional arrangements such as local government planning powers, voluntary actions, regulatory practices, and more; organizational structures such as democratic and accountable systems, and access to high levels of government; maintenance of effective coordination of civil and professional science; development of shared visions across all institutional levels, based on careful problem analyses; and importantly, long-term funding for organizational development [12] [14].

\section{The GWAM Conceptual Framework}

Building on the existing body of knowledge of the bottom-up and the top-down approaches, the tenet of GWAM is to overcome the limitations in both approaches while retaining and effectively integrating their advantages.

The overall conceptual design of the GWAM framework is shown in Figure 1 below. As the figure illustrates, the ultimate goal of the framework is to achieve sustainable watershed management in accommodating urbanization, the associated issues of which include flooding, low flow, water pollution, sedimentation, and habitat destruction. Towards this goal, the GWAM model promotes and sustains effective integration of the science from technical experts and the local knowledge, governmental policy making and funding with local collaboration, decision making, and actions. The non-governmental organizations (NGOs), environmental stewards, and private contributions are also built into the GWAM model in recognition of their key role in many environmental issues.

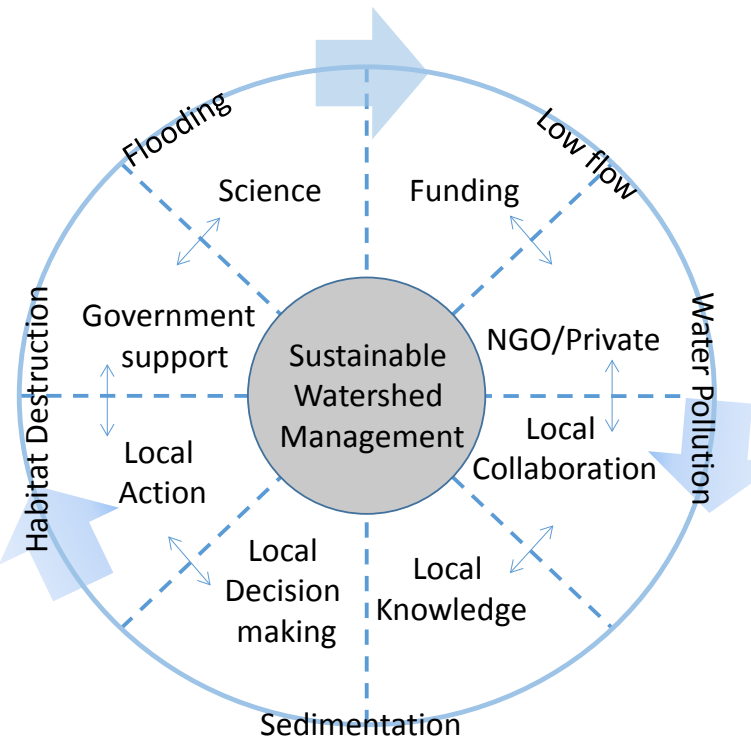

Figure 1. Conceptual design of the GWAM model for sustainable urbanization management. 


\subsection{Common Platform}

The first and foremost component of the GWAM model is a common platform where all parties convene. The platform will ensure that all parties maintain meaningful involvement in the decision-making process. This means that each party not only receives the invitation to participate, but also utilizes the platform for careful deliberation and for sharing and implementing the results of technical analysis [18]. Under GWAM, this platform will play a key role in bringing 3C approach of stakeholders to address issues related to land use change and urbanization. Government agencies, NGOs, grass-root level organizations, and private citizens can also actively participate and contribute to the watershed management processes through this platform.

\subsection{Partnership}

A second key component of the GWAM model is the identification and involvement of the partnership from at least two major groups of the stakeholders in a watershed [19]. The first group is composed of private residents, environmental stewards, watershed groups, non-governmental organizations and local legislators and politicians. Flooding, drought, and/or water quality related issues in the watershed motivate this group, because their life are directly or indirectly impacted by these issues. The second group is composed of local, state, and government employees, who are often responsible to implement and enforce the regulations and/or government programs. This group could also include academics. This group is mainly motivated through regulations and job functions. Participation of the first group is extremely important for identifying and recognizing issues that threaten the waterbodies. The first group also generates the momentum to bring the attention of political and governmental higher ups to make appropriate decision-making in new regulations, policies and funding mechanisms in local and federal levels. The participation of the second group is equally important for enforcing regulations and policies and carrying out necessary actions to address the issues. The two major groups in a GWAM setup, along with the linkages between the two groups are demonstrated in Figure 2. As shown in the Figure, while the two groups have different motivations in a GWAM unit, they share the same goal of watershed protection and restoration.

\subsection{Facilitation}

A third key component of the GWAM model is the mechanism for effective facilitation among the parties. A successful watershed management program can only be sustained through appropriately facilitating differently motivated stakeholders toward a common goal, addressing the issues to protect and restore the waterbodies. Organizational and functional structures have to accommodate the exchange of ideas and to encourage democratically acceptable decision-making. One major format of facilitation are regular meetings, which can be either quarterly or monthly meetings. Regular meetings are crucial for maintaining a 

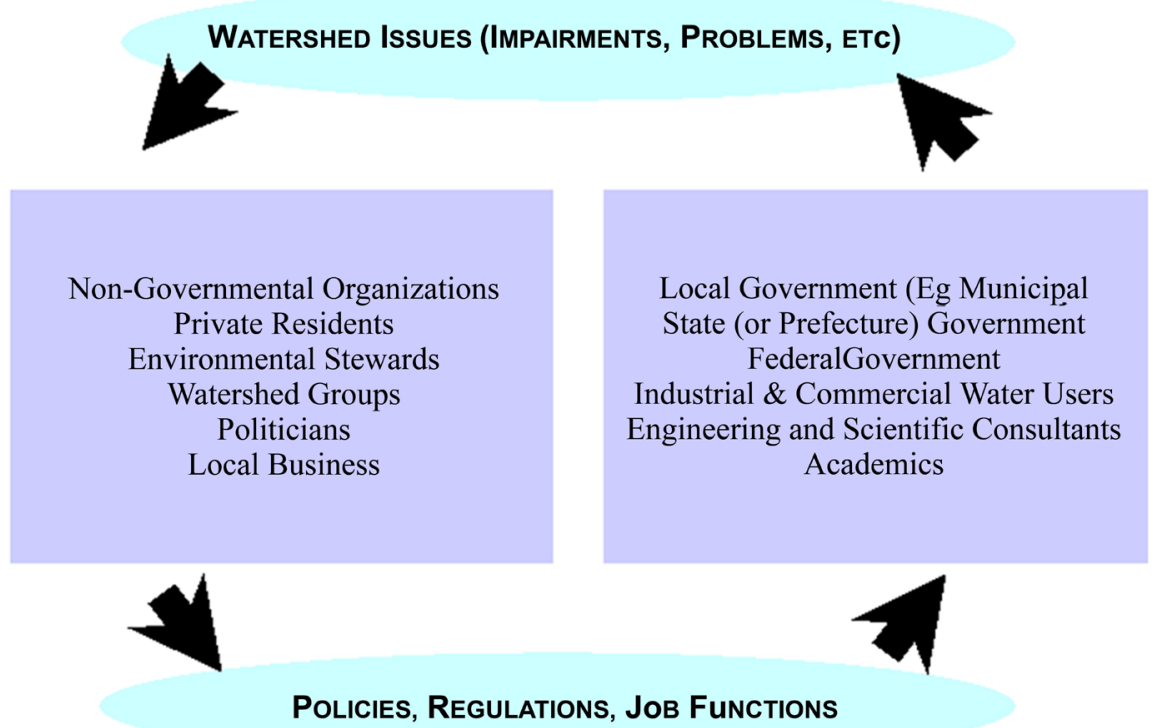

Figure 2. Linkage of the partnership from stakeholders motivated by issues and policies, regulations, and job functions in a GWAM unit.

dynamic and vibrant water management decision-making process. Through regular meetings, a systematic cycle of steps (Figure 3) can be applied to address water related issues in a watershed. As shown, the cycle of steps are consisted of problem identification, problem recognition, problem investigation for implementation planning, and problem solving through implementing actions. Although the cycle is fundamentally similar to well-known Deming's Plan-DoCheck-Act (PDCA) model, it focuses on addressing the issues associated with natural resources management that require long term response to every action rather than focusing on industrial production process. Thus, it includes one or more internal PDCA cycle(s) in every step. Problem identification step involves the process of detecting an issue and bringing it to get the needed attention towards addressing it. For example, conducting a screening level water quality sample collection under problem identification is part of planning stage of a large PDCA cycle of watershed management. However, sample collection itself includes another internal PDCA cycle of developing a sample collection plan, executing it, checking and adopting needed changes, and implement it until it reaches to the level of identifying the issue. Similarly other steps, problem recognition that is the process of making all stakeholders accept the issue and commit towards resolving it, problem investigation/implementation planning that is the process of reaching a level where clear remedial and implementation actions can be determined, and problem solving/implementing action that is the process of executing the remedial or preventing action to solve the issue, can have its own internal PDCA cycles. In addition, it requires integrating related regulations and stakeholders in the decision makings at every step. As a result, the four major steps are intended to address a water management issue in the long term 


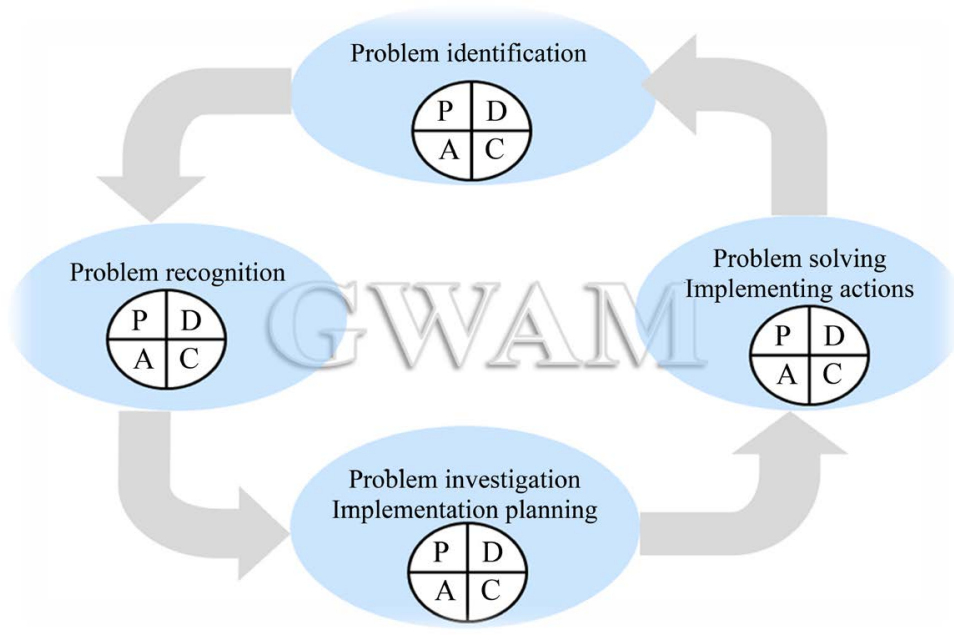

Figure 3. A systematic cycle of steps to address the issues in GWAM. Each step may include one or more internal Plan-Do-Check-Act cycle(s).

with appropriate integration of stakeholder involvement. While the four components represent individual phases of solving water related issues in a watershed, the regular meetings are the bond to link one component to another and to advance the decision making process. At each step, scientific analysis (for example [6]) can provide necessary understanding and stakeholder conciseness to move to the next step towards successful management. Through this cycle, priority issues can be continuously identified and addressed through the $3 \mathrm{C}$ approach that is core to the GWAM model.

\subsection{Conceptual Framework}

GWAM is proposed for assisting decision-makers to improve watershed management, especially addressing the impacts of urbanization. The institutional model overcomes the common limitations posed in both the traditional top-down approach and the more recent bottom-up approach, and instead emphasizes on effective collaboration between government agencies and local stakeholders. The GWAM model consists of three major components: a permanent platform for all parties to interact and to communicate, a partnership that consists of at least two major stakeholders in the watershed, and a facilitation mechanism that sustains the model for long-term operations. These components could be viewed as the base (permanent platform), the pillar (facilitation), and the beam (partnership) of the structure of a pendulum balance that is used to weigh things (Figure 4). GWAM Framework provides the structure and process to conduct the balancing act of appropriate decision making by the stakeholders towards sustainable watershed management.

\section{Conclusions}

The urbanization process exerts negative multidisciplinary impacts on the integrity of natural watershed conditions. These impacts are best analyzed and 


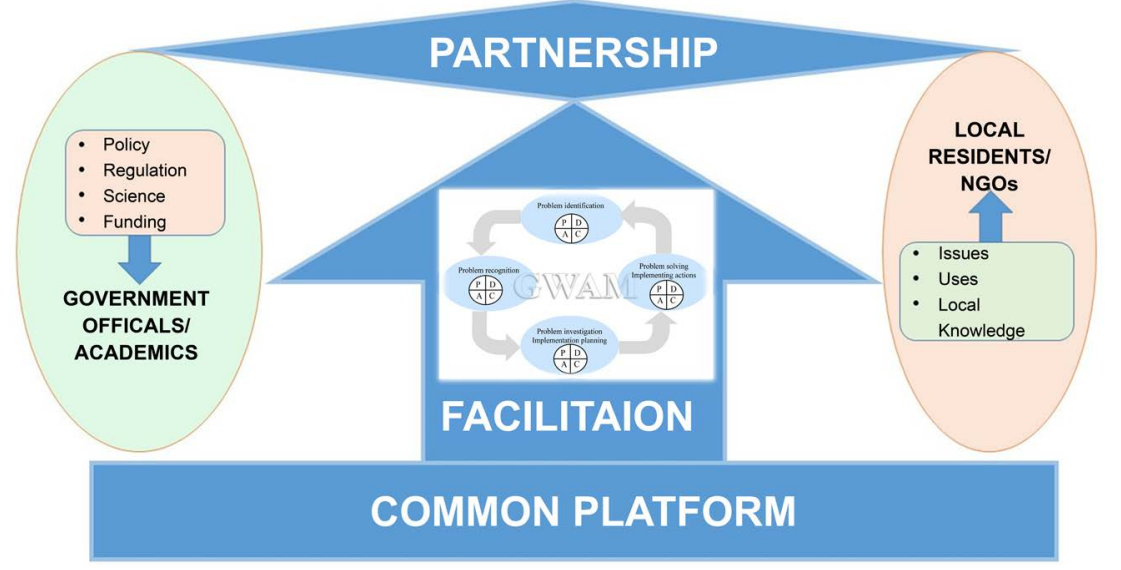

Figure 4. GWAM Conceptual Framework as a pendulum balance, with base (common platform), beam (partnership among major stakeholder group) and pillar (facilitation), to perform the balancing act of sustainable watershed management.

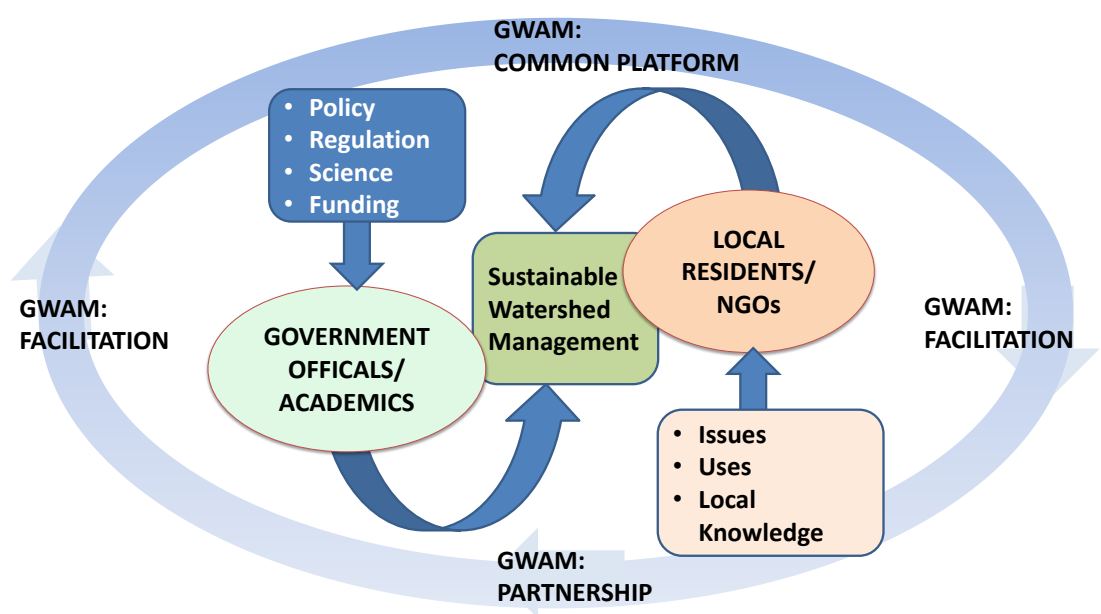

Figure 5. Conceptual self-sustaining GWAM model with effective integration of the governmental agencies and institutes at the top and the local residents and non-governmental organizations at the bottom towards sustainable watershed management.

addressed with local inputs, as many of these are site specific and require consistent local monitoring along with appropriate policies and regulations from conventional governance in an interdisciplinary platform. GWAM is to establish a self-sustaining and effective institutional forum that can be used in watersheds across geographical and political boundaries while accommodating the urbanization process.

With effective integration of the governmental agencies and institutes at the top and the local residents and non-governmental organizations at the bottom, the concept is that the hybrid approach can serve as a self-sustaining model in achieving effective management of urbanization impacts (Figure 5). Integration of science in every step of decision making and facilitation of acquired knowledge in regular meetings with all stakeholders are considered key aspects in sustaining the bond among differently motivated stakeholders towards the same 
goal of watershed protection.

The objective of this paper is to present the concept of GWAM institutional model. As applicable to any model, GWAM should be tested and validated before applying it as a general institutional model in watershed management. Investigations in detail on the major components of GWAM, common platform to conduct the management, partnership of two major stakeholder groups from government and non-governmental organizations, and the facilitation mechanisms are recommended to gain the needed understanding on structure, process and function of a successful GWAM. A companion paper [20] is published in the same issue that validated GWAM through a field implementation in the Shawsheen Watershed in Massachusetts, USA.

\section{Acknowledgements}

The authors would like to express our gratitude for Dr. Guoshun Zhang, for his time in reviewing the research and providing valuable feedback. The constructive comments provided by the anonymous reviewers also helped improving the paper and are greatly appreciated.

\section{Conflicts of Interest}

The authors declare no conflicts of interest regarding the publication of this paper.

\section{References}

[1] Leopold. L.B. (1968) Hydrology for Urban Land Planning-A Guidebook on the Hydrological Effects of Urban Land Use. US Geological Survey Circular, 554, 18 p.

[2] Hollis, G.E. (1975) The Effect of Urbanization on Floods of Different Recurrence Interval. Water Resources Research, 11, 431-435. https://doi.org/10.1029/WR011i003p00431

[3] USEPA (US Environmental Protection Agency) (1983) Results of the Nationwide Urban Runoff Project: Final Report. US EPA, Office of Water, Washington DC.

[4] Booth, D.B. (1991) Urbanization and the Natural Drainage System-Impacts, Solutions, and Prognoses. The Northwest Environmental Journal, 7, 93-118.

[5] Quilb'e, R., Rousseau, A.N., Moquet, J.S., Savary, S., Ricard, S. and Garbouj, M.S. (2008) Hydrological Responses of a Watershed to Historical Land Use Evolution and Future Land Use Scenarios under Climate Change Conditions. Hydrology and Earth System Sciences, 12, 101-110. https://doi.org/10.5194/hess-12-101-2008

[6] Saravanapavan, T., Yamaji, E., Voorhees, M. and Zhang, G. (2014) Using Hydrology as a Surrogate in TMDL Development for Impairments Caused by Multiple Stressors. Advances in Water Resource and Protection, 2, 1-10.

[7] Thomas, D.E. (2008) Where Central Policies Meet Local Objectives: Exploring Sub-Basin-Level Participatory Watershed Management in Northern Thailand. Proceedings of the Sustainable Sloping Lands and Watershed Management Conference, 12-15 December 2006, In: Gebbie, L., Glendinning, A., Lefroy-Braun, R. and Victor, M., Eds., National Agriculture and Forestry Research Institute (NAFRI), Vientiane.

[8] Agrawal, A. and Gibson, C. (2001) The Role of Community in Natural Resource 
Conservation. In: Agrawal, A. and Gibson, C., Eds., Communities and the Environment, Ethnicity, Gender and the State in Community-Based Conservation, Rutgers University Press, New Brunswick, 1-23.

[9] Smith, J.L. (2008) A Critical Appreciation of the "Bottom-Up" Approach to Sustainable Water Management: Embracing Complexity Rather than Desirability. Local Environment, 13, 353-366. https://doi.org/10.1080/13549830701803323

[10] Heyd, H. and Neef, A. (2004) Participation of Local People in Water Management: Evidence from the Mae Sa Watershed, Northern Thailand. Environment and Production Technology Division, International Food Policy Research Institute, Washington DC.

[11] Lane, M.B. and McDonald, G. (2005) Community-Based Environmental Planning: Operational Dilemmas, Planning Principles and Possible Remedies. Journal of Environmental Planning and Management, 48, 703-731.

https://doi.org/10.1080/09640560500182985

[12] Lovell, C., Mandondo, A. and Moriarty, P. (2002) The Question of Scale in Integrated Natural Resource Management. Conservation Ecology, 5, 25.

https://doi.org/10.5751/ES-00347-050225

[13] National Research Council (2001) Envisioning the Agenda for Water Resources Research in the Twenty-First Century. The National Academies Press, Washington DC.

[14] Hooper, B.P. (2003) Integrated Water Resources Management and River Basin Governance. Water Resources Update, 126, 12-20.

[15] Selin, S. and Chevez, D. (1995) Developing a Collaborative Model for Environmental Planning and Management Environmental Management. Environmental Management, 19, 189-195. https://doi.org/10.1007/BF02471990

[16] Huntington, C.W. and Sommarstrom, S. (2000) An Evaluation of Selected Watershed Councils in the Pacific Northwest and Northern California. (3 Parts). Prepared for Trout Unlimited and Pacific Rivers Council, Eugene.

[17] Genskow, K.D. and Born, S.M. (2006) Organizational Dynamics of Watershed Partnerships: A Key to Integrated Water Resources Management. Journal of Contemporary Water Research and Education, 135, 55-64. https://doi.org/10.1111/j.1936-704X.2006.mp135001007.x

[18] Hammond, J.S., Keeney, R.K. and Raifa, H. (1999) Smart Choices: A Practical Guide to Making Better Decisions. Harvard Business School Press, Boston.

[19] Kontogianni, A., Tziritis, I. and Skourtos, M. (2005) Bottom-Up Environmental Decision Making Taken Seriously: Integrating Stakeholder Perceptions into Scenarios of Environmental Change. Human Ecology Review, 12, 87-95.

[20] Saravanapavan, T. and Yamaji, E. (2018) GWAM-An Institutional Model to Address Watershed Impacts from Urbanization: Field Validation. Journal of Water Resources and Protection, 10, 906-918. https://doi.org/10.4236/jwarp.2018.109053 